\title{
Aykırı Sözlükler
}

\author{
Fatih DOĞRU**
}

\section{Aykırı Sözlükler}

Özet

Bir dilin söz varlığını barındıran temel başvuru kaynakları olan sözlükler hazırlanış amaçlarına ve oluşturulma tekniklerine göre farklı kategorilere ayrımaktadır. Hazırlanan sözlüğün tek dilli ya da çok dilli olması, alfabetik ya da tematik olarak düzenlenmesi, ele aldığı söz varlı̆ının niteliği (genel sözlük, lehçe sözlüğü, terim sözlüğü, eşanlamlılar sözlüğü vb.) gibi ölçütlere göre bu kategoriler oluşturulmaktadır. İçeriği (mizah), üslubu (yergi) ya da formatı (alfabetik olmayan düzenleme) ile beklenen ölçütlerden ayrılan bir başvuru kaynağı olarak tanımlanan aykırı sözlükler de hazırlanış amacı ve oluşturulma tekniği itibariyle farklı bir sözlük kategorisi olarak görülmektedir. Aykırı sözlükler bilinen bu kategorilerin dışına çıkan ve mizahi/eleştirel bir içeriğe sahip olan, alışılageldik tanımların yerine sıra dışı tanımların yer aldığı sözlüklerdir. Aykırı sözlüklerin en temel özelliği hem sözlüğün tanımlarındaki, hem hazırlanış yöntemindeki hem de sözlüğü oluşturan veritabanındaki sıra dışılıktır. Yapılan tanımların alışıımış sözlük tanımlarından farklı olmasının yanı sıra bu tanımlarda alaycı, mizahi, eleştirel ve kimi zaman da toplumsal değerlere ters düşen bir yaklaşım görülür. Bu çalışmada aykırı sözlügün ne olduğu; Türkiye'de ve Dünyadaki belli başlı aykırı sözlüklerin hangileri olduğu ve bunların özellikleri üzerinde durulacaktır.

Anahtar Kelimeler: Aykırı sözlük, Sözlük, Sözlükbilim, Sözlük türleri

\section{Giriş}

Sözlükler bir dilin söz varlığını barındıran temel başvuru kaynaklarıdır. Bu başvuru kaynakları farklı kullanım amaçları için çeşitli teknikler kullanılarak hazırlanabilirler. Kullanım amaçlarına ve hazırlanış şekillerine göre sözlükler farklı kategorilere ayrılabilir. Hazırlanan sözlüğün tek dilli ya da çok dilli olması, alfabetik ya da tematik olarak düzenlenmesi, ele aldığı söz varlığının niteliği (genel sözlük, lehçe sözlüğü, terim sözlüğü, eşanlamlılar sözlüğü vb.) gibi ölçütlere göre bu kategoriler

*Bu çalışma II. Uluslararası Türkçe Konuşan Öğrenciler Kongresinde sözlü bildiri olarak sunulmuştur. **Fatih DOĞRU, Arş. Gör., Eskişehir Osmangazi Üniversitesi, Fen-Edebiyat Fakültesi, fatihdogru.ogu@gmail.com.tr 
Fatih DOĞRU

oluşturulmaktadır. Bu çalışmada ele alacağımız "aykırı sözlükler” ise bilinen bu kategorilerin dışına çıkan ve mizahi/eleştirel bir içeriğe sahip olup alışılageldik tanımların yerine sıra dışı tanımların yapıldığı sözlüklerdir.

Béjoint sözlük türlerini açıklarken “sözlüklerin diğer türleri” başlığı altında aykırı sözlüklerin (anti-dictionaries) kelime listelerinden şekilsel olarak ayrılan bir tür olduğunu söyler ve şu ifadeleri kullanır:

Üretici dönüşümsel gramerciler herhangi bir dilde cümleler üretmek için kullanılan kurallar kümesine eklenecek olan bir kelime listesinden yararlanabilirler. Bu bazen sözlükçe (lexicon) bazen de sözlük (dictionary) olarak adlandırılır. Oluşturulan cümleleri boş alan içine sığdırmak amacıyla her kelime için gerekli olan bilgiler tamamen bilinmemektedir. Çünkü genellikle bu elle tutulur bir nesne değildir. Aslında hiç kimse bir sözlükçeyi ya da onun yayınlanmış herhangi bir alt bölümünü kullanmaz. Sözlükçe örnekleri içeren kitaplar gerçekte tek başlarına sözlük değillerdir. Ayrıca veri bankası uzmanları veri bankası içindeki bilgilerin konumu için işaretçiler olarak kullanılan anahtar sözcük listeleri olan ve bazen de kelime listesi (thesauri) olarak adlandırılan sözlükleri kullanırlar. Bu tür bir şekilde kullanılmayan sözcük listesi "aykırı sözlük" olarak adlandırılır (1994; 26).

Hartmann ve James ise aykırı sözlüklerin içeriği, üslubu ve formatının farklılığına dayanarak bir tanım yapmışlardır. Onlara göre aykırı sözlüklerin tanımı ve bu türde daha önce yazılmış örnekler şöyledir:

İ̧eriği (mizah), üslubu (yergi) ya da formatı (alfabetik olmayan düzenleme) ile beklenen ölçütlerden ayrılan bir başvuru kaynağıdır. Paolo Beni tarafından yazılan The Anticrusca (Venice, 1612), italyan Akademi sözlüğü The Vocabolario degli Accademici della Crusca'nın eleştirel bir tahliliydi; R.F. Gillet'in yazdığı Le Porte-feuille'nin (Madrid, 1762) derleyicilerinin ve sözlüğün olumsuz değerlendirmeleri yüzünden; Ambrose Bierce'nin yazdığı Şeytan'ın Sözlügüünün (Devil's Dictionary) (1906) ise olay yaratan konuların alaycı tanımları sebebiyle adı kötüye çıkmıştı. Alfabetik olmayan düzenlemelerinden dolayı bir "antidictionary" olarak tematik bir kavram dizinine (thesaurus) gönderme yapmak mümkündür (1998; 6).

Bu tanım ve örneklerden anlaşılacağı üzere aykırı sözlüklerin en temel özelliği; sözlüğün tanımlarındaki, hazırlanış yöntemlerindeki ve sözlüğü oluşturan veritabanındaki sıra dışlıktır. Yapılan tanımların alışılmış sözlük tanımlarından farklı olmasının yanı sıra bu tanımlarda alaycı, mizahi, eleştirel ve kimi zaman da toplumsal değerlere ters düşen bir yaklaşım görülür. 


\section{Batı'da ve Türkiye'de Aykırı Sözlük Örnekleri}

\section{1. Batı'da Aykırı Sözlük Örnekleri}

Aykırı sözlüklerin en meşhurlarından olan Ambrose Bierce'nin yazmış olduğu Şeytanın Sözlügü’nde (Devil's Dictionary) genel anlamda sözlükler kötü niyetli bir araç, hatta dilin gelişmesinin önündeki bir engel olarak görülürken Bierce'nin kendi yazmış olduğu "aykırı sözlük" niteliğindeki sözlük ise yazılan en yararlı çalışmalardan biri olarak görülmüştür. Bierce, bu sözlüğünde "sözlük" maddesini şu şekilde tanımlamıştır:

Sözlük (Dictionary), Bir dilin büyümesini engelleyen, o dili zor ve esnemez hale getiren art niyetli edebi bir araç. Oysa elinizdeki sözlük, onun yazarı Dr. John Şeytan'ın bugüne kadar kaleme aldığı en yararlı çalışmalardan biridir. Bu sözlük, tamamlandığı güne kadar bilinen her şeyin kısa ve sade bir özeti olacak şekilde tasarlanmıştır ve bir vidayı sıkacaktır, kırmızı renkli bir yük vagonunu tamir edecektir ya da bir boşanma işinde uygulanacaktır. Kızamık yerine gayet güzel geçer ve sıçanları deliklerinden çıkarıp öldürtür. Solucanlar için de ölümcül bir vuruştur ve çocuklar bunun için ağlarlar (2005; 234).

1842 'de Amerika Birleşik Devletleri'nde doğmuş ve iç savaşta yer alarak binbaşılık rütbesine kadar gelmiş bir asker olan, pek çok öyküsü de bulunan ve 1913'de Meksika'ya giderek orada gizemli bir şekilde yaşamını yitiren Bierce'in yazdığı Şeytanın Sözlüğ̈̈ ${ }^{1}, 1881$ yılında haftalık bir gazetede yayımlanmaya başlamış ve uzun aralıklarla 1906 yılına kadar yayımlanmaya devam etmiştir. Bu sözlük, 1906 yılında Kiniğin (Alaycının) Sözlüğü (The Cynic's Word Book) adıyla kitap haline getirilmiş, daha sonra yazarın içine sinmeyen bu başlık 1911'de Şeytanın Sözlüğü olarak değiştirilerek tekrar yayımlanmıştır.

Döneminin şartları düşünüldüğünde toplumsal yapıya ters düşen ve dile getirilmekten çekinilen pek çok konunun gündeme getirildiği bir içeriğe sahip olan sözlükte zaman zaman bazı maddeler tanımlandıktan sonra altlarına, yapılan tanımla bağlantılı olarak yazarın seçtiği bazı şairlerin şiirlerinden de örneklere yer verilmiştir. Yazar, bu sözlüğüne yazdığı önsözünde bu şiirlerle kitabın daha dikkat çekici ve keyifli bir hale geldiğini söyler.

Scognamillo da bu sözlüğe yazdığı önsözde bu kitabın bir mizah (kara mizah) çalışması olduğunu, Bierce'in yaşam bilgisini, yaşam tecrübesini büyük bir zevkle ve acımasız bir yaklaşımla değerlendirdiği bir yapıt olduğunu söyler. Ona göre Bierce, dünyaya ve insanlığa, insanlığın kabul ettiği değerlere, toplumsal alışkanlıklara tümden aykırı ama kendi içinde doğru bir bakışla bakmış ve sonuçları bu sözlüğe aktarmıştır (Bierce, 2005; 9).

\footnotetext{
${ }^{1}$ Ambrose Bierce ve Şeytanın Sözlüğü hakkında Celal Üster'in 31.03.2006'da Radikal Gazetesi'nde yayımladığı “Yeryüzü Kitaplığı" başlıkı yazısında yazar ve eseri ile ilgili ayrıntılı bilgi bulunmaktadır.
} 
Fatih DOĞRU

Bu sözlük bugün sanal ortamda da erişilebilir durumdadır². Bu sözlükten sonra aykırı sözlük olarak nitelendirebileceğimiz Şeytanın Sözlüğü adıyla yayımlanan başka sözlükler de ortaya çıkmıştır. Bunlar arasında T. J. Mc Allister'ın yazdığı Şeytanın Yeni Sözlüğü (New Devil’s Dictionary) ${ }^{3}$ ve Sherman P. Wright'a ait Şeytanın Sözlüğü projesi gösterilebilir. Ayrıca Ambrose Bierce ve Chaz Bufe tarafından yazılmış, Şeytanın Sözlüğü'nden seçmelerin bulunduğu ve Amerikan Heretiğinin Sözlüğü'nün yer aldığı Şeytanın Sözlükleri (The Devil’s Dictionaries) adlı sözlük de bu bağlamda ele alınabilir.

Şeytanın sözlüğü adıyla değil, doğrudan doğruya antidictionary adıyla yayımlanmış bir sözlük de bulunmaktadır. Cromwell, The Anti-dictionary adlı sözlügünde toplumsal, kültürel, teknolojik vb. etkenlerle ölen ve ölmekte olan sözcükleri ele almış, bu sözcükleri alfabetik olarak sıraladıktan sonra, önce sözcüğün MSN Encarta çevrimiçi sözlüğünde ve Marriam Webster'in onuncu baskısında verilen tanımlarını göstermiş, daha sonra da bu sözcüklerin ölüşlerini ya da ölmekte oluşlarıyla ilgili gidişatını sebepleriyle anlatmıştır. Yazar bu sözlüğünde anlam ve kavram alanı olarak değeri düşmüş ve kullanım sıklığının da giderek azaldığını düşündüğü kelimeleri öznel bir bakış açısıyla derlediğini söylemektedir (2002; xi).

Hazırlanış yöntemi olarak daha farklı bir yol izleyen, tanımlarını çeşitli aforizmalardan oluşturduğu için bir aforizma kitabı olarak da görülebilecek John Lloyd ve John Mitchinson'ın (2008; ix) hazırladığı "Afili Lügat” (Advanced Banter) ve Agnes Michaux’un hazırladığı "Kadın Düşmanı Sözlük" (Dictionnaire Misogyne) de birer aykırı sözlük olarak görülebilirler. Yazarlarının "Afili Lügat" için yazdığı önsözde bu kitabın ünlü yazar ve düşünürlerin aforizmalarından oluştuğu ancak bir referans kitabı olmadığı, bunun bir manifesto olduğu belirtilmiştir. Michaux (2010; 11) da "Kadın Düşmanı Sözlük" için "gülünç, sebepsiz yere saldırgan ama çoğu kez komik ve her zaman gerçeğe o kadar da aykırı değil” tanımlamasını yapar. Her iki kitabın da alfabetik bir şekilde düzenlendiği ve belli başıklar altında o konuyla ilgili ünlü yazar ve düşünürlerin sözlerini içerdiği görülmektedir.

Örnek (Michaux, 2010; 46):

beter

Dünyada bir kadından daha beter bir şey olamaz, tabii başka bir kadın hariç.

Aristophanes, Thesmophoriazouosai

(Thesmophoria Bayramını Kutlayan Kadınlar), MÖ V. Yüzyıl

\section{2..2. Türkiye'de Aykırı Sözlük Örnekleri}

Türkçe yazılmış, aykırı sözlük olarak nitelendirebileceğimiz sözlükler de bulunmaktadır. Mehmed Celâl'in yazdığı "Sevdâ Lûgati”, Levent Tülek'in hazırladığı "Lumpen Sözlügüu”, A. Ali Ural'ın

\footnotetext{
${ }^{2}$ http://www.thedevilsdictionary.com

${ }^{3}$ http://www.counter-currents.com/2012/11/new-devils-dictionary

${ }^{4}$ http://sherwright.com/Devils_Dictionary.htm
} 
hazırladığı "Tek Kelimelik Sözlük”, A. Serap Fırat'ın hazırladığı "Romantik Sözlük” ve Gülşah Özdemir'in hazırladığı "Türkçe Kadın Sözlüğü" ve "Türkçe Erkek Sözlüğü" gibi sözlükler de birer aykırı sözlük olarak görülebilirler.

Şeytanın sözlüğü adlandırması kullanılarak Türkçe yazılan, Sabri Kaliç’in düzenlediği Şeytanın Türkçe Sözlüğü de bu sözlüklerden biridir. Karakalem dergisinde tefrika edilmeye başlayan bu sözlük zamanla genişletilerek kitap haline getirilmiştir. Alfabetik olarak dizilmiş sözlükte sözcüklerin tanımları, bilindik şekillerinin dışında, mizahi, iğneleyici ve eleştirel bir yaklaşımla yapılmıştır. Bu sözlük de diğer "şeytanın sözlükleri" gibi bir kara mizah örneği olarak görülebilir.

Mehmed Celâl'in Sevdâ Lûgati, alfabetik olarak (Arap alfabesine göre) hazırlanmış bir sözlüktür. Madde başlarını oluşturan "sevda" ile ilgili sözcüklerin açılaması yapıldıktan sonra o sözcüklerle ilgili mısra, beyit ve şiir parçalarından örnekler verilmiştir. Bu şiirlerden Mehmed Celâl'e ait olanların şairi belirtilmemiş ve bu şiirler tırnak içinde gösterilmemiştir. Ayrıca her madde başının yanında açıklanılan sözcükle ilgili bir çizim bulunmakta ve bu çizimlerin de Mehmed Celal'e ait olduğu düşünülmektedir. Çeşitli şairlerden örnekler barındıran sözlük, toplam 261 madde başından oluşmaktadır $(2003 ; 9)$.

Örnek (Celâl, 2003; 13):

\section{âteş}

Duygulu gönüllerde söndürülmesi pek zor olan ve için için yanan bir alevdir. Bu sözcük, yaşlı bir şairi bu şiir ile dile getirir:

Görüp bu kül gibi yüzümü, bilmezsin

Ne âteş olduğumu, ben de kendi çağımda

Tülek, Lumpen Sözlüğü'nü hazırlarken yerleşik bir jargon ve argodan ayrı bir lumpen dilinin sözlüğünü hazırladığını söyler ve sözlüğün yazınsal ve bilimsel bir tavırdan ziyade bir bakış, bir değerlendirme ve daha çok da eğlenceli eleştirel bir derleme olarak görülmesini ister. Sözlükte kullanılan dil, yerleşik olmayan bir kültürün var ettiği, "içinde bulunduğu toplumun kültürüne yabancı düşen, sözde bilgili tutum ve davranışlarıyla itici olan" kimselerin kullandığı "lumpen" ${ }^{5}$ dilidir (2007; $5-6)$.

Örnek (Tülek, 2007; 14):

\section{ateşlemek}

Birine para vermek. Koltuk çıkmak. Destek vermek. Sigara istemek anlamında da kullanilır.

Ör: Baba ordan bir on kağıt ateşle be... Berbere gidip bir faça yapalım!

Ural’ın hazırladığı “Tek Kelimelik Sözlük” ise alfabetik olarak düzenlemiş belli konularda yazılan denemelerden oluşmaktadır. Ural, sözlüğünde madde başı olarak aldığı tek bir sözcükten yola

\footnotetext{
${ }^{5}$ Lümpen sözcüğü "sınıfsız" ve "ayaktakımı" (TDK, 2011; 1595) olarak tanımlanmaktadır.
} 
Fatih DOĞRU

çıkmış ve bu sözcüğü deneme yoluyla tanımlamıştır. Daha çok deneme türüne aitmiş gibi görünse de bu eser aynı zamanda tematik bir sözlüktür de. Bu kitapta da hem hazırlanışı hem de içeriği itibariyle alışılageldik sözlük ölçütlerinden farklı ölçütler kullanılarak aykırı sözlük özelliği görülmektedir.

Fırat da Romantik Sözlük'te, romanlardan alıntıladığı sözleri, alfabetik olarak sıraladığı konu başlıklarının altında vermektedir. Ona göre oluşturduğu bu sözlük "aynı sözcüklerin hemen her sözlükte aynı şekilde ifade edildiği güvenli standartların aksine, okuruyla oyun oynayan bir metin" içermektedir. Öte yandan Fırat, kendi sözlügünü, her duyguyu ya da olguyu çok yönlü açıklayabilen, alabildiğine somut bir sözlük olarak tanımlamaktadır (2007; ix). Bu sözlükte de Afili Lügat'te olduğu gibi farklı şair, yazar ve düşünürlerin ilginç sözlerine yer verilmiş ve bunlar tematik olarak düzenlenmiş̧ir.

Örnek (FIrat, 2007; 246):

\section{sözcük}

Ama ben onu pek dinlemiyor, sözlerinin zavllı yaralı kuşlar gibi yere düşmelerine aldırmıyordum.

Andre GIDE, Dar Kapı, s.129

Sözlü dünya benden ayrı dururdu hep. O zaman bir kuşku düşüverdi içime. Başkaları, bu sözlü dünya ile duygu dünyaları arasında bir birlik kurabiliyorlar mıydı gerçekten? Ben mi dışında kalıyordum bunun? Yoksa bir yalancılığı mı sürdürüyorduk hepimiz?

Melih Cevdet ANDAY, İsa'nın Güncesi

Sararmış bıyıkları altından bir takım laf kırıntılarını geveleyip duruyordu.

Albert CAMUS, Yabancl, s.57

Özdemir'in hazırladığı Türkçe Kadın Sözlüğü (2006) ve Türkçe Erkek Sözlüğü (2006)’nde kadınlar ve erkekler kendilerine mahsus bir takım özelliklerden hareketle sınıflandııımış ve bu sınıflandırmaya dayanarak çeşitli tanımlar yapılmıştır. Alfabetik olarak düzenlenmiş bu sözlüklerin madde başları kadın veya erkeklere ait sıfatlardan oluşmaktadır (Cilveli Kadın, Cesur Erkek vb). Tanımlarda ise yazarın bu sıfatlara sahip kadın ve erkekler hakkındaki kanaatlerine yer verilmiştir.

Örnek (Özdemir, 2006b; 90):

\section{örnek erkek}

Örnek erkek; büyüklerine saygılı, küçüklerine sevgili, vatanına ve milletine bağlı, başarıll, kültürlü, soylu bir erkek tipidir. Muhalif, sorgulayıcı, düşündürücü hiçbir olaya girmez. Birisi ona "zor geçiniyoruz" dese komünistlik ve anarşistlikle suçlar. Para bitirmek, kredi kartı puanlarını yükseltmek, aldığı elektronik eşyalarla hava atmak en 
büyük zevkidir. Sahip olduğu malın kölesidir. Kendisinden güçsüz olanları ezer, güçlüye boyun eğer. Kendisini asgari ücretle çalıstıran patronuna da vefa borcu duyar. $O$ tam bir vatan evladıdır.

Bugünkü katılımlı sosyal medya sözlükleri de içerikleri bakımından bir tür aykırı sözlük olarak görülebilirler. Pek çok katılımlı sosyal medya sözlüğünde yazarlar, kendi yazarı oldukları sözlüğü, daha önce yazılmış olan aykırı sözlüklerin paraleli hatta daha gelişmişi olarak görmektedir. Yapılan tanımlara ve üsluplarına bakıldığında Ekşi Sözlük, Uludağ Sözlük, İtü Sözlük, İnci Sözlük gibi katıımlı sosyal medya sözlükleri de birer aykırı sözlüktür. Bu sözlüklerde sözlüğe daha önce üye olan yazarlar, açılan konu başıkları altında kendi hayat tecrübelerine dayanarak zaman zaman mizahi, eleştirel, iğneleyici ve alaycı bir üslupla, zaman zaman daha nesnel ve faydacı olma kaygısıyla çeşitli tanımlar yapmaktadır. Yazarlar bu tanımları yaparken belirledikleri rumuzları kullanmakta ve bu sebeple tanımlarını daha özgür bir biçimde aktarabilmektedirler. Sözlükte yazar olmak için herhangi bir ayrıcalığa gerek olmaması ve herkesin bu sözlüklerde yazar olabilmesi, sözlük yazarlarının standart bir profile sahip olmalarını önlemiş, kadın ya da erkek, her meslekten, her yaştan, her siyasi görüşten, her etnik gruptan ve dünyanın her yerinden insanlar bu sözlüklerde kendi tanımlarını yapabilmişlerdir. Pek çok internet kullanıcısının hemen hemen her konuda bilgi sahibi olmak amacıyla başvurduğu bu kaynaklarda, bireysel konularda pek çok tanım bulunacağı gibi toplumsal olaylar hakkında da farklı görüşler yer almaktadır.

Örnek (eksisozluk.com):

sözlük

güzelliği, zaman kaybettirmesinde olan faydalı kitap. tek bir kelimenin anlamına bakmak için açarsını, başka kelimelere gözünüz takılır. en güzeli de günlük hayatta sürekli karşılaştığınız ıvır zıvırların ismini genellikle bu şekilde öğrenebilirsiniz.

\section{Sonuç}

Uzun bir geçmişe sahip olan sözlük geleneği, bireysel ya da toplumsal bazı sebeplerle bir takım değişikliklere uğratılmış ve alışımış ölçütlerinin dışında, farklı üslup ve bakış açılarıyla değiştirilerek yeni bir sözlük türü oluşturulmuştur. Aykırı sözlük adı verilen bu sözlük türü, içerdiği bazı öznel, alaycı ve eleştirel tanımlarından dolayı bazı çevrelerce kabul görmemiş ancak zamanla kendi okur/kullanıcı kitlesini bulmuştur. Teknolojinin gelişmesi, internet olanaklarının artması, dünyada giderek bireysel yaşantının daha çok öne çıkması gibi sebepler, farklı üslupta yazıımış olan bu aykırı sözlüklere olan ilgiyi de arttırmıştır. İçinde bulunduğu topluma, genel kabul görmüş pek çok değere, sosyal ve siyasi düzene aykııı düşen, sıra dışı yazarların sıra dışı tanımlar yaptığı bu sözlükler, alışıımış sözlüklerin betimleyici özelliğinin aksine dünyayı ve insanları değiştirme iddiası taşırlar. Batı'da ve Türkiye'de pek çok örneğine rastladığımız bu sözlükler, yalnızca başvuru kaynakları olarak değil aynı zamanda edebi değere sahip eserler olarak da görülebilirler. 
Fatih DOĞRU

\section{Kaynaklar}

Béjoint, H. (1994). Modern Lexicography An Introduction, Oxford University Press, New York.

Bierce, A. (2005). Şeytanın Sözlüğü (Çev: Cemal Atilla), Omega Yayınları, İstanbul.

Bierce, A. ve Bufe, C. (2004). The Devil's Dictionaries, The Best of The Devil's Dictionary and The American Heretic's Dictionary, See Sharp Press, Tucson, AZ.

Celâl, M. (2003). Sevdâ Lûgati (Günümüz diline aktaran: Sevengül Sönmez), Okuyan Us Yayınları, İstanbul.

Cromwell, M. (2002). The Anti-dictionary, A Selected List of Words Being Forced From The Modern Lexicon, Writers Club Press, USA.

Fırat, A. S. (2007). Romantik Sözlük, Sinemis Yayınları, Ankara.

Hartmann, R.R.K. ve James, G. (1998). Dictionary of Lexicography, Routledge, London.

Kaliç, S. (2012). Şeytanın Türkçe Sözlüğü, Etik Yayınlar, İstanbul.

Lloyd, J. ve Mitchinson, J. (2008). Afili Lügat (Çev: Duygu Akın), Domingo Yayınları, İstanbul.

Michaux, A. (2010). Kadın Düşmanı Sözlük (Çev: Yiğit Bener), Can Yayınları, İstanbul.

Özdemir, G. (2006a). Türkçe Kadın Sözlüğü / Türkçe-Kadın Kadın-Türkçe, Akis Kitap, İstanbul.

Özdemir, G. (2006b). Türkçe Erkek Sözlüğü / Türkçe-Erkek Erkek-Türkçe, Akis Kitap, İstanbul.

TDK (Kurul) (2011). Türkçe Sözlük, Türk Dil Kurumu Yayınları, Ankara.

Tülek, L. (2007). Lumpen Sözlügüü, Sel Yayınclık, İstanbul.

Ural, A.A. (2011). Tek Kelimelik Sözlük, Şule Yayınları, İstanbul.

Üster, C. (1996). "Yeryüzü Kitaplı̆ı̆”, Radikal Gazetesi,

http://www.radikal.com.tr/ek_haber.php?ek=ktp\&haberno=5055 Erişim tarihi: 20.11.2012.

http://www.thedevilsdictionary.com (Erişim tarihi: 20.11.2012).

http://www.counter-currents.com/2012/11/new-devils-dictionary (Erişim tarihi: 20.11.2012).

http://sherwright.com/Devils Dictionary.htm (Erişim tarihi: 20.11.2012).

https://eksisozluk.com/sozluk--32786?p=8 (Erişim tarihi: 19.10.2014). 